University of Nebraska - Lincoln

DigitalCommons@University of Nebraska - Lincoln

Nebraska Cooperative Fish \& Wildlife Research Nebraska Cooperative Fish \& Wildlife Research Unit -- Staff Publications

Unit

$3-27-2020$

\title{
Weather and Exposure Period Affect Coyote Detection at Camera Traps
}

\author{
Anastasia E. Madsen \\ University of Nebraska-Lincoln, amadsen6@unl.edu \\ Lucia Corral Hurtado \\ University of Nebraska-Lincoln, Icorral@huskers.unl.edu \\ Joseph J. Fontaine \\ University of Nebraska-Lincoln, jfontaine2@unl.edu
}

Follow this and additional works at: https://digitalcommons.unl.edu/ncfwrustaff

Part of the Aquaculture and Fisheries Commons, Environmental Indicators and Impact Assessment Commons, Environmental Monitoring Commons, Natural Resource Economics Commons, Natural Resources and Conservation Commons, and the Water Resource Management Commons

Madsen, Anastasia E.; Corral Hurtado, Lucia; and Fontaine, Joseph J., "Weather and Exposure Period Affect Coyote Detection at Camera Traps" (2020). Nebraska Cooperative Fish \& Wildlife Research Unit -Staff Publications. 298.

https://digitalcommons.unl.edu/ncfwrustaff/298

This Article is brought to you for free and open access by the Nebraska Cooperative Fish \& Wildlife Research Unit at DigitalCommons@University of Nebraska - Lincoln. It has been accepted for inclusion in Nebraska Cooperative Fish \& Wildlife Research Unit -- Staff Publications by an authorized administrator of DigitalCommons@University of Nebraska - Lincoln. 


\title{
Weather and Exposure Period Affect Coyote Detection at Camera Traps
}

\author{
Anastasia E. Madsen, Lucia Corral, and Joseph J. Fontaine
}

Nebraska Cooperative Fish \& Wildlife Research Unit, University of Nebraska-Lincoln, School of Natural Resources, 3310 Holdrege Street, Lincoln, NE 68583, USA.

Correspondence: amadsen1213@gmail.com

\begin{abstract}
Camera traps are an increasingly popular means to monitor wildlife populations. However, like other techniques for measuring populations, camera traps are subject to sources of error that may bias population estimates. Past studies accounting for detection error have failed to account for a simple but potentially widely pervasive source of environmental error: weather conditions. Using 5,108,416 photographs from 804 scent-lured camera traps deployed in western Nebraska, USA, during spring and autumn of 2014 and 2015, we analyzed the relationship between weather conditions (barometric pressure, wind speed, precipitation, and temperature) and coyote (Canis latrans) detection probability. Using binomial generalized linear mixed-effects models, we showed that detection probability was affected by all weather conditions examined. Weather effects on detection suggests that either weather alters coyote behavior or decreases trap efficacy. Detection probability also decreased over the exposure period, indicating that coyotes either avoided traps after initial exploration or that lure efficacy decreased over time. Our findings suggest that to achieve accurate population indices, camera-trap studies need to incorporate effects of weather conditions and sampling duration into population models to account for detection bias in estimates.
\end{abstract}

Keywords: camera trap, Canis latrans, coyote, detection probability, occupancy modeling, weather, wildlife monitoring.

Published in Wildlife Society Bulletin 44:2 (2020), pp 342-350.

DOI: $10.1002 /$ wsb.1080

Copyright (c) 2020 The Wildlife Society. Published by John Wiley. Used by permission. Submitted 3 October 2018; accepted 1 December 2019; published 27 March 2020. 
Wildlife monitoring is an integral component of ecological studies because it is necessary to observe animals in a natural setting to gain a fundamental understanding of ecological processes. From complex field experiments to agency mandated ecological surveys, the need for accurate means to monitor wildlife has resulted in a variety of methods to observe and survey wildlife (Seber 1986, Borchers et al. 2002). Point counts, for example, collect species counts from designated locations and use the resulting data to calculate a population index that is assumed to be proportional to the actual population size (Pollock et al. 2002). Although efficient, point counts and similar in-person surveys are labor-intensive and not efficient for rare, elusive, and neophobic species.

Camera traps have been used as a scientific method for studying wildlife since the early 2oth century (Kucera and Barrett 2011). As equipment has become more advanced and more affordable, camera traps have become a commonly used and cost-effective means of monitoring wildlife populations (Trolliet et al. 2014). Camera traps require less labor than other survey methods, allowing data to be collected over large spatial and temporal extents (Silveira et al. 2003, Tobler et al. 2008). Cameras are also less invasive than methods that involve disturbing an area over an extended time or methods with frequent human presence, which makes them well-suited for monitoring rare or elusive species. From 1998 to 2008, the number of published studies using camera traps grew 5 -fold, with many studies focused on estimating the abundance or the distribution of wildlife populations (O'Connell et al. 2006, 2011; Rowcliffe and Carbone 2008; Tobler and Powell 2013; Tobler et al. 2015).

However, despite the monitoring benefits afforded by camera traps, this method has several limitations. Photo resolution, trigger settings, camera placement, and more can influence the quantity and quality of images, and ultimately, detection rates (Rovero et al. 2013). Similarly, the behavior and size of an animal can affect the likelihood of detection (Tobler et al. 2008, Sollmann et al. 2013). Camera traps are an increasingly popular method of monitoring species of conservation concern; thus, failure to account for detection error can affect regulatory enforcement, mitigation efforts, and conservation success if occupancy and density models systematically underestimate populations (e.g., Carbone et al. 2001, 2002; MacKenzie et al. 2002; Rowcliffe et al. 2008). 
Population indices calculated from field surveys are known to be affected by detection error, but, as of 2001, only half of vertebrate studies accounted for detection probability in models (Kellner and Swihart 2014). Indeed, despite an awareness that camera traps are themselves susceptible to Type II error (i.e., the failure to detect an animal that is present; Hamel et al. 2013, Pease et al. 2016), many studies using camera traps still fail to incorporate detection into modeling efforts (O'Connell et al. 2011, Foster and Harmsen 2012). Studies that incorporate detection error in models largely focus on accounting for technical error, landscape features, and spatial bias (MacKenzie et al. 2002, Burton et al. 2015). Environmental conditions, such as weather, also affect animal detection by altering animal behavior or camera function, but the relationship between weather and camera-trap detection rates is largely unknown (Gooch et al. 2006, Kays et al. 2011, Bacheler et al. 2014).

Although many canid populations in the United States are thriving (e.g., coyote [Canis latrans] and red fox [Vulpes vulpes]), others are not (e.g., red wolves [C. rufus] and swift fox [V. velox]; Ripple et al. 2014, Albrecht 2015, Faust et al. 2016). The increased prevalence of camera traps as a tool to study canid species may suggest that such studies are at risk to underestimate canid population sizes if the importance of detection probability is disregarded. Failing to account for detection probability could lead to inaccurate population estimates, reducing the efficacy of canid conservation plans (McCallum 2013). Indeed, detection rates are extremely low for rare species, making it onerous to estimate and account for Type II error (Foster and Harmsen 2012). If managers are to monitor rare species effectively, it is necessary to identify sources of error that affect monitoring efforts to improve study design and modeling efforts.

Common species with broad ecological and behavioral profiles may provide robust data to identify sources of error that may be applicable to similar, but rare, species (Caro 2010). For example, sources of Type II errors affecting detection rates of a common species, such as the coyote, can be applied to rare canids such as swift fox or red wolves. Universal environmental variables such as weather could similarly affect detection of sympatric canid species, although inferences regarding these relationships should be approached with caution (Wiens et al. 2008). Coyotes are generalist carnivores that are broadly distributed over the majority of North America (Bekoff and Gese 2003). 
Although coyotes live in a variety of environments, they tend to select habitats with woods, draws, and other means of permanent cover, and frequently reuse areas for diel cover (Andelt and Andelt 1981). Primarily nocturnal and crepuscular, coyotes can be active during the day (McClennen et al. 2001). The high abundance of coyotes relative to other carnivores made the coyote an ideal candidate to explore sources of variation in detection rates.

We studied the effects of weather and exposure period on detection rates of coyotes in western Nebraska, USA. We asked how weather affects our understanding of coyote populations and subsequently the species for which they may act as surrogates. We built 3 models based on hypotheses for the correlation between weather variables and detection probability of coyotes. The first candidate model included a single weather predictor, air temperature, based on the hypothesis that temperature accounts for the majority of the variance in detection probability because environmental temperature limits numerous behavioral and physiological processes across taxa (Fry 1967). We predicted that the response to temperature would show a normal distribution, where extreme high and low temperatures would have markedly lower detection probability than intermediate temperatures. The second candidate model included barometric pressure and precipitation as predictor variables, including an interaction term because both variables are associated. We hypothesized that barometric pressure would act as a cue for animals to predict precipitation, leading to lower activity levels, which we then predicted would correspond to decreased detection probability (Brown et al. 1957). The third candidate model was a global model that included temperature, barometric pressure, precipitation, and wind speed as predictors. We hypothesized that all weather conditions combined would affect detection probability more than any single variable. We predicted that the global model would explain the most variance compared with our other models because it included the cumulative effects of all weather conditions. Our study investigated the interactions among weather conditions, exposure period, and detection of an elusive species at camera traps to better understand how environmental variables affect wildlife survey and population modeling efforts. 


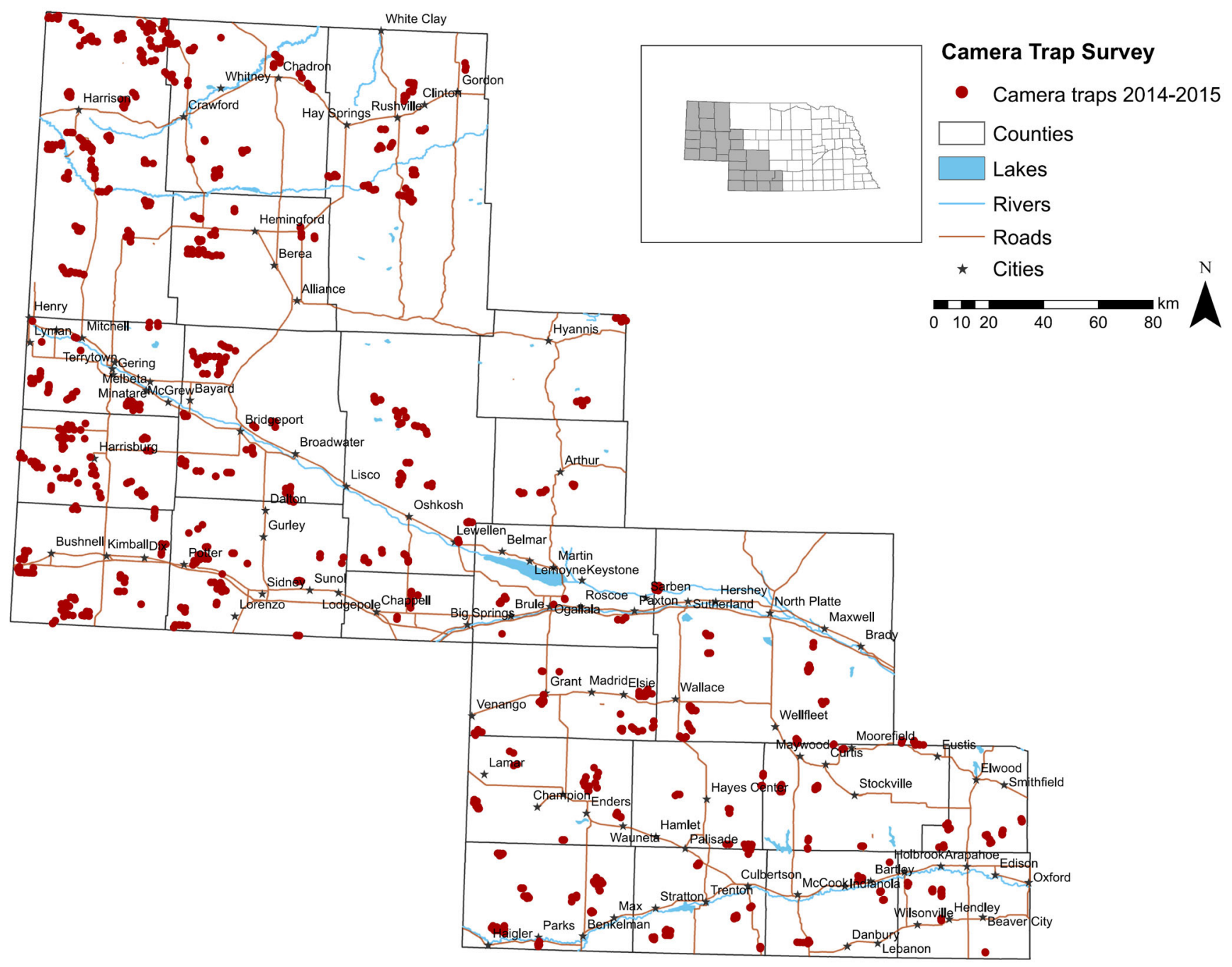

Figure 1. Motion-triggered camera traps were deployed throughout 24 counties in western Nebraska, USA, to collect occupancy data on multiple Canidae and other mesocarnivore species, including the coyote. Individual sites varied between 4 field seasons: Spring 2014 (21 Mar-18 Jun), Autumn 2014 (5 Sep-7 Nov), Spring 2015 (26 Mar-20 Jun), and Autumn 2015 (31 Aug-21 Dec).

\section{Study area}

Our study area spanned 24 counties in western Nebraska, an area of approximately 68,605 km² (Fig. 1), for spring (Mar-Jun) and autumn (Sep-Dec) seasons of 2014 and 2015 (Table 1). The topography of the study site featured rolling hills, plains, sand hills, and escarpments, 
Table 1. Average weather conditions by season for western Nebraska, USA, from the Nebraska Mesonet System for each of 4 field seasons: Spring 2014 (21 Mar-18 Jun), Autumn 2014 (5 Sep-7 Nov), Spring 2015 (26 Mar-20 Jun), and Autumn 2015 (31 Aug-21 Dec).

\begin{tabular}{|c|c|c|c|}
\hline Field season & Weather condition & $\bar{x}$ & $S E$ \\
\hline \multirow[t]{5}{*}{ Spring 2014} & Diurnal air temp $\left({ }^{\circ} \mathrm{C}\right)$ & 10.86 & 2.21 \\
\hline & Nocturnal air temp $\left({ }^{\circ} \mathrm{C}\right)$ & 4.91 & 1.90 \\
\hline & Daily precipitation (mm) & 1.20 & 1.10 \\
\hline & Daily wind speed $(\mathrm{km} / \mathrm{hr})$ & 15.85 & 1.18 \\
\hline & Daily barometric pressure $(\mathrm{Pa})$ & $2,728.00$ & 290.79 \\
\hline \multirow[t]{5}{*}{ Autumn 2014} & Diurnal air temp $\left({ }^{\circ} \mathrm{C}\right)$ & 13.10 & 1.83 \\
\hline & Nocturnal air temp $\left({ }^{\circ} \mathrm{C}\right)$ & 5.83 & 1.52 \\
\hline & Daily precipitation (mm) & 0.30 & 0.70 \\
\hline & Daily wind speed $(\mathrm{km} / \mathrm{hr})$ & 12.07 & 1.20 \\
\hline & Daily barometric pressure $(\mathrm{Pa})$ & $3,037.00$ & 10.32 \\
\hline \multirow[t]{5}{*}{ Spring 2015} & Diurnal air temp $\left({ }^{\circ} \mathrm{C}\right)$ & 10.29 & 1.60 \\
\hline & Nocturnal air temp $\left({ }^{\circ} \mathrm{C}\right)$ & 3.83 & 1.33 \\
\hline & Daily precipitation (mm) & 0.80 & 1.00 \\
\hline & Daily wind speed $(\mathrm{km} / \mathrm{hr})$ & 14.04 & 1.30 \\
\hline & Daily barometric pressure (Pa) & $3,203.00$ & 248.51 \\
\hline \multirow[t]{5}{*}{ Autumn 2015} & Diurnal air temp $\left({ }^{\circ} \mathrm{C}\right)$ & 41.75 & 1.73 \\
\hline & Nocturnal air temp $\left({ }^{\circ} \mathrm{C}\right)$ & 8.10 & 1.35 \\
\hline & Daily precipitation $(\mathrm{mm})$ & 0.40 & 0.70 \\
\hline & Daily wind speed $(\mathrm{km} / \mathrm{hr})$ & 10.97 & 1.13 \\
\hline & Daily barometric pressure (Pa) & $4,065.00$ & 336.34 \\
\hline
\end{tabular}

and soil types varied from sandy to calcareous (Anderson 1999, Chapman et al. 2001). The plains of western Nebraska consisted of mixed-grass and shortgrass prairie (Tieszen et al. 1997, Bishop et al. 2011) represented by the shortgrass prairie and Sandhills ecoregions (Schneider et al. 2011). The northwest region was covered by native grasslands, $87 \%$ of which was used for grazing livestock. The southwest and central panhandle regions of the shortgrass prairie were increasingly converted to cropland (88\%; Schneider et al. 2011), with a majority of land dedicated to corn (Zea mays), and soybeans (Glycine max; Wright and Wimberly 2013). The elevation of the study area ranged from $329 \mathrm{~m}$ above sea level in the northwest to $1,654 \mathrm{~m}$ above sea level in the southwestern Panhandle region (Nebraska Department of Natural Resources 1969). The regional climate was semiarid, receiving 30-40 cm of precipitation annually (Schneider et al. 2011), with average wind speeds of $14^{-24} \mathrm{~km} /$ hour, average winter temperatures ranging from $-7^{\circ}$ to $-4^{\circ} \mathrm{C}$, and average summer temperatures ranging from $22^{\circ}$ to $26^{\circ} \mathrm{C}$ (Anderson 1999). 


\section{Methods}

\section{Camera Traps}

We deployed 65 Bushnell Trophy Cam HD (model 119437; Bushnell Outdoor Products, Overland Park, KS, USA) and 377 Moultrie M-88o (model MCG-12594; Moultrie Feeders, Birmingham, AL, USA) brand cameras to monitor coyotes over 4 field seasons. Locations for camera traps were selected based on the presence of fences, minor roads, intersections, and other suspected coyote travel routes to increase detection probability (Barja et al. 2004, Whittington et al. 2005). We laid a grid over the study area using squares of $31 \mathrm{~km}^{2}$ and classified the grid by the percentage of land cover. We then used a Reverse Randomized Quadrant-Recursive Raster algorithm (ESRI ArcGIS Version 10.4.1.5686; Environmental Systems Research Institute, Inc., Redlands, CA, USA) to randomly sample the grid via an unequal inclusion probability, which takes into account the potential spatial pattern of the population and optimizes sampling based on the probability of observing a target species in a specific point given the percentage of land cover (i.e., allowed us to spatially balance sites while also choosing locations with $\geq 25 \%$ short- and mixed-grass prairie). Cameras were separated by $\geq 1.6 \mathrm{~km}$ to reduce detections of the same individual at multiple sampling locations.

For deployment, we secured each camera to a fence post, tree, pole, or wooden stake $40 \mathrm{~cm}$ from the ground using screws and steel camera boxes or nylon straps from the manufacturer. We placed a wooden stake $3 \mathrm{~m}$ from the camera with $40 \mathrm{~cm}$ of the stake above ground. We placed approximately $15 \mathrm{~mL}$ of striped skunk (Mephitis mephitis) lure on the top of each stake, level with the camera. We made the lure by heating and solidifying a mixture of petroleum jelly and skunk essence (385mL jelly:15 mL essence; F\&T Fur Harvester's Trading Post, Alpena,MI, USA). Skunk lure is a long-range lure effective in attracting a variety of carnivore species, including coyote, on account of the attractiveness of fatty acid scent (Andelt and Woolley 1996, Schlexer 2008). Lures may alter animal behavior, but we handled no animals in the course of this study and scent lures complied with the standards of ethical treatment of animals (Sikes et al. 2011). We set cameras to take a series of 3 pictures when motion or heat signature was detected (i.e., burst-shot setting), and set them 
to take burst shots every 5 seconds while the subject was in range (Table S1, in Supporting Information).We deployed cameras for a minimum of 10 days in an effort to both maximize detection and reduce Type II error. We redeployed cameras at multiple sites within the same seasons to maximize the area covered with the number of cameras available to us. Over all 4 seasons, we deployed 804 camera-trap sites.

\section{Image Processing}

We individually processed photographs within the image processing software Timelapse Image Analysis (Greenberg 2012). The use of Timelapse decreased the likelihood for human error during the highly repetitive process of examining photographs while allowing information for each photograph to be automatically recorded in a spreadsheet for subsequent analysis. We trained technicians to identify and mark species using the Timelapse software over the course of 2 weeks and analyzed all photographs used for training twice, making corrections when necessary. Technicians identified animals in each photograph using reference photographs and physical descriptions of the species as well as the $40-\mathrm{cm}$-tall wooden stake for size comparison. The resulting outcome was a binary series of detections (presence marked 1 and absence marked o) for coyotes for every hour of camera deployment at each site.

\section{Weather Data}

We collected hourly weather data from weather stations in western Nebraska via the Nebraska Mesonet system, a contributor to the Automated Weather Data Network that includes data for states in the High Plains Region (https://hprcc.unl.edu/awdn.php). We paired each camera-trap site with the nearest weather station data using the nearest neighbor function in ArcGIS. We created an hourly grid of occupancy and weather data using the paired sites and weather stations in the Program R environment (R Version 3.5.0, www.R-project.org, accessed 23 Apr 2018). 


\section{Data Analysis}

We fit a series of generalized linear mixed effects models using a binomial logit link function in the R package lme4 (Bates et al. 2015). For each model, we used coyote occupancy as the response variable, exposure period as a predictor variable, and 2 random effects variables: date and time represented as a single vector, and a statewide grid that defined the location of each camera-trap site in terms of Township, Range, and Section. The pool of predictor variables included air temperature $\left({ }^{\circ} \mathrm{C}\right)$, precipitation $(\mathrm{mm})$, barometric pressure $(\mathrm{Pa})$, and wind speed $(\mathrm{km} / \mathrm{hr})$. The final candidate model was a null model for comparison. We evaluated models for parsimony using Akaike's Information Criterion (AIC) in which the model with the lowest AICc was identified as the most parsimonious and selected as the top-ranked model (Akaike 1973). We also evaluated the contribution of each predictor to the global model using the MuMIn package (Barton 2019), which used a stepwise selection method to calculate the amount of variance explained by each predictor (Table S2, in Supporting Information). The top model was used to predict the probability of coyote detection for both real and simulated weather conditions.

\section{Results}

We collected 5,499,619 pictures from 804 camera traps over the course of 4 field seasons. We removed 152,520 photographs because they were corrupted or lacked necessary metadata (e.g., timestamp) for analysis. Of the photographs collected, 13,838 contained $\geq 1$ coyotes $(14,063$ coyotes counted; Fig. 2). Cameras were active for a mean period of 11.078 days ( \pm 0.115$)$ over the entire study period, resulting in 26,143 camera-trap days (sum of days all cameras were deployed over the entire study period) across 303 calendar days (days of the calendar year in which $\geq 1$ camera was deployed).

Hourly data from 14 weather stations were downloaded from the Nebraska Mesonet system, resulting in 6,643 hours over 281 calendar days of weather data for the final analysis. We removed 238,683 additional photographs that could not be paired with weather data from the analysis, leaving 5,108,416 photographs over 281 calendar days 


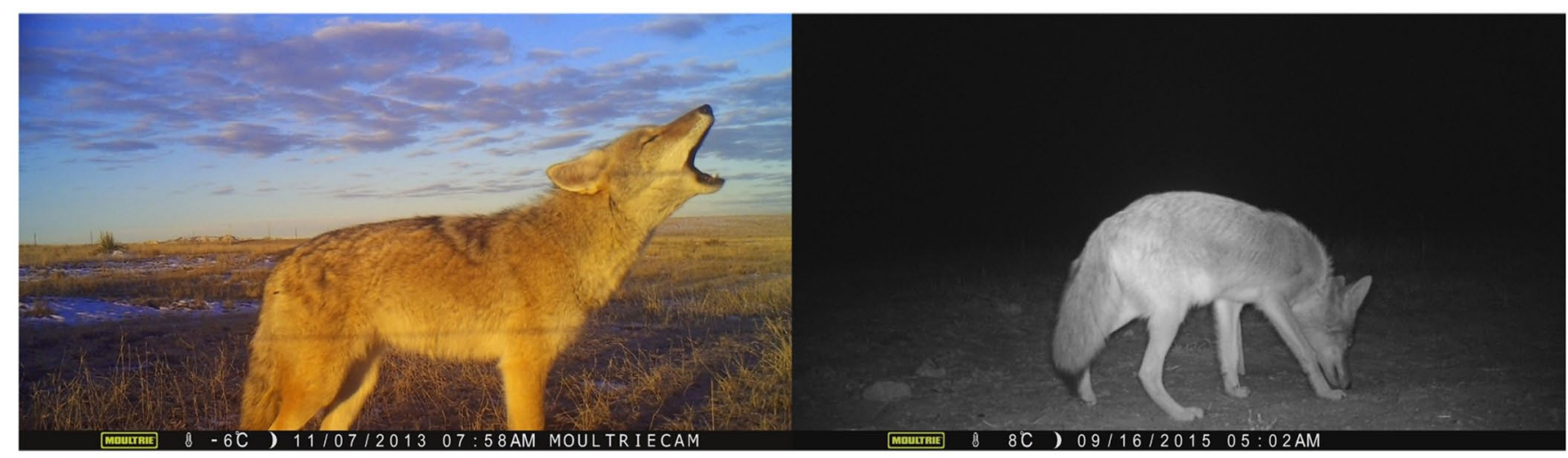

Figure 2. Coyotes photographed by motion-triggered camera traps in western Nebraska, USA. Camera traps were deployed for 4 field seasons: Spring 2014 (21 Mar18 Jun), Autumn 2014 (5 Sep-7 Nov), Spring 2015 (26 Mar-20 Jun), and Autumn 2015 (31 Aug-21 Dec).

for the analysis. Average weather conditions for the study period remained within normal ranges for the region (Table 1).

We selected the global model as the top model (Table 2, Table S2). All weather variables we considered affected detection probabilities, with air temperature, precipitation, and wind speed negatively correlated with detection probabilities, and barometric pressure positively correlated (Table 3, Fig. 3). Detection probability also showed a negative relationship with the exposure period (Table 3, Fig. 3).

Table 2. Akaike's Information Criterion corrected for small sample size (AICc) results of candidate generalized linear mixed-effects models examining the effects of weather predictors and exposure period on coyote occupancy in western Nebraska, USA, over 4 field seasons: Spring 2014 (21 Mar-18 Jun), Autumn 2014 (5 Sep-7 Nov), Spring 2015 (26 Mar-20 Jun), and Autumn 2015 (31 Aug-21 Dec).

\begin{tabular}{|c|c|c|c|c|c|}
\hline Model & $K^{\mathrm{a}}$ & $A I C_{\mathrm{c}}^{\mathrm{b}}$ & $\Delta A I C_{c}^{c}$ & Weight $^{\mathrm{d}}$ & Log likelihood \\
\hline $\begin{array}{l}\text { Exposure period }+ \text { temperature }+ \text { precipitation } \\
\quad+\text { pressure }+ \text { wind speed }\end{array}$ & 8 & $16,399 \cdot 57$ & 0.00 & 1 & $-8,191.79$ \\
\hline Exposure period + temperature & 5 & $16,538.14$ & 138.57 & $\mathrm{o}$ & $-8,264.07$ \\
\hline Exposure period + pressure $\times$ precipitation & 6 & $16,591.97$ & 192.40 & o & $-8,281.84$ \\
\hline Null & 3 & $16,598.65$ & 199.08 & $\mathrm{o}$ & $-8,296.33$ \\
\hline
\end{tabular}
a. No. of parameters.
b. Akaike's Information Criterion corrected for small sample sizes.
c. Difference from the top model in Akaike's Information Criterion corrected for small sample sizes.
d. Model weight.
e. Logarithmic likelihood: goodness of fit measurement. 
Table 3. Estimated parameters from the selected generalized linear mixed effects model. Weather and exposure period predictors showed significant effects on coyote occupancy probability in western Nebraska, USA, over 4 field seasons: Spring 2014 (21Mar-18 Jun), Autumn 2014 (5 Sep-7 Nov), Spring 2015 (26 Mar-20 Jun), and Autumn 2015 (31 Aug-21 Dec).

\begin{tabular}{lrrrr} 
Predictor & Estimate & $S E$ & $Z$ & $P$ \\
\hline (Intercept) & -6.683 & 0.077 & -87.03 & $<0.001$ \\
Air temp & -0.240 & 0.035 & -6.88 & $<0.001$ \\
Precipitation & -0.178 & 0.062 & -2.87 & 0.004 \\
Wind speed & -0.387 & 0.038 & -10.30 & $<0.001$ \\
Barometric pressure & 0.123 & 0.048 & 2.56 & 0.011 \\
Exposure period & -0.105 & 0.033 & -3.22 & 0.001 \\
\hline
\end{tabular}

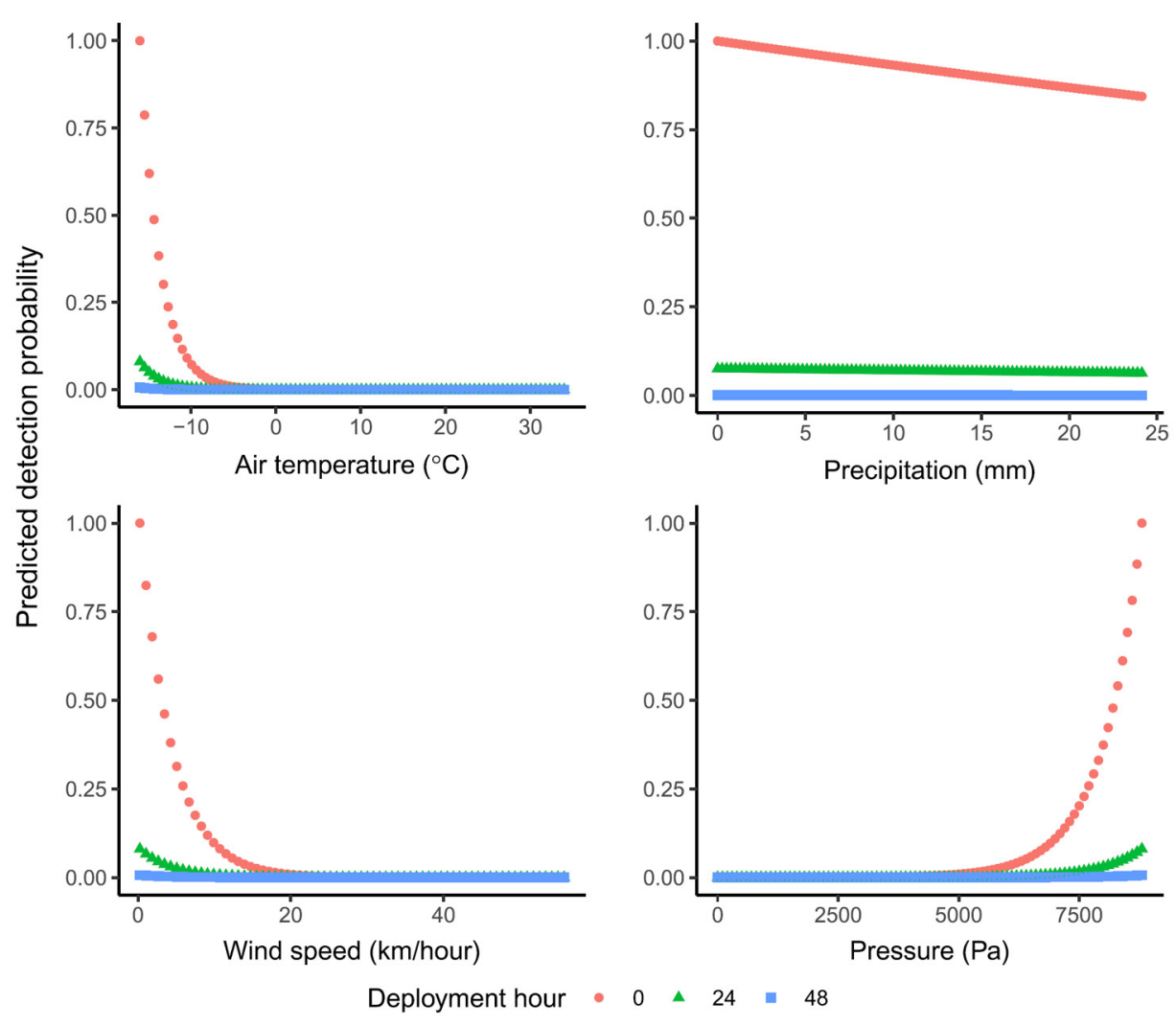

Figure 3. Detection probability of coyotes in western Nebraska, USA, at motiontriggered camera traps as predicted by the interaction between days deployed and temperature, precipitation, wind speed, or pressure. Detection probabilities are separated by the amount of time in the exposure period (o hr, $24 \mathrm{hr}$, and $48 \mathrm{hr}$ ). Probabilities were calculated based on the top-performing generalized linear mixed-effects model using prediction data frames in which each predictor varied individually while remaining predictors held constant at the mean. Probabilities were calculated for predictors within the range of the collected data. Camera traps were deployed for 4 field seasons: Spring 2014 (21 Mar-18 Jun), Autumn 2014 (5 Sep-7 Nov), Spring 2015 (26 Mar-20 Jun), and Autumn 2015 (31 Aug-21 Dec). 


\section{Discussion}

We found that detection probability decreased exponentially as the exposure period increased. Indeed, there was a near zero predicted probability of detecting a coyote after a trap was deployed for 24 hours. The rapid decline in detection we documented is surprising because other studies have suggested that detect rates actually increase with exposure period (Larrucea et al. 2007), presumably because human scent and activity associated with setting up the camera has dissipated (Séquin et al. 2003). Unlike other studies, however, our study relied on a lure station to attract coyotes to the camera (e.g., Larrucea et al. 2007). Our high initial detection rates may speak to the efficacy of scent lures for monitoring canids, but the rapid rate of decline in detections suggests that lures may have limited benefits for longterm deployment either because of declining potency or target animals quickly identify lures as fake. The differences among study designs in temporal patterns of detection may call into question the ability to compare results from camera trap studies with even slight differences in methodology, but more importantly the differences highlight the need to account for detection probability in efforts to model population size or distribution using camera trap data (Guillera-Arroita et al. 2014, Burton et al. 2015).

Air temperature, wind speed, and barometric pressure all elicited threshold responses on predicted detection probability. The threshold relationships suggest that there are critical points for each weather predictor at which coyote detection probability exponentially increases. In contrast, the linear relationship between precipitation and detection probability shows that precipitation may reduce movement over a range of activity levels, possibly because movement in response to precipitation is subject to great individual variation. Both the threshold and continuous effects on detection probability can be accounted for during survey design and the modeling process to correct for the confounding effects of weather and yield more accurate population estimates.

Weather conditions have the potential to affect the reliability and effectiveness of technology, including remote cameras. Extreme temperatures, rain, fog, snow, and even high wind events can obscure photos, reduce camera trigger efficiency, or even cause camera failure (Long et al. 2008, Meek et al. 2014). The large number of photos 
we did not include in our analysis (3\%) may in part speak to how weather affects the efficacy of camera traps, but because we removed corrupt pictures from our analysis they cannot explain the patterns we document between weather and detection probability. Moreover, sources of weather-related technological failure such as precipitation events were rare in our system, and temperature conditions during the study were well within the normal operating ranges of the cameras we deployed.

A more parsimonious explanation for the relationships we see among weather variables and detection probability is that weather affected animal movement (Kauhala et al. 2007, Noonan et al. 2015). The negative correlation with temperature may be a result of animals compensating for increased energy demands at lower temperatures by increasing foraging rates or by otherwise increasing movement (Bailey 1971, Dillon and Kelly 2008). Similarly, the positive correlation with barometric pressure suggests that coyotes may use barometric pressure as a cue to predict precipitation, resulting in a decrease in movement just before a precipitation event (Paige 1995, Lytle 1999). Because wind speed has a negative correlation with detection probability, we suggest that wind speed may interfere with olfaction performance of a largely olfactory-driven predator (i.e., that wind disturbs the normal dispersal of the skunk lure; Algar et al. 2007), or that low winds require coyotes to increase movement to forage. Effects of wind are likely correlated with wind direction in addition to wind speed, and wind direction was not used in our models (Wells and Bekoff 1982).

Advances in modeling techniques have made it easier to account for variable detection probability during analysis (MacKenzie et al. 2002, 2003; Bailey et al. 2014), but understanding sources of detection error can also help to optimize detection probability by accounting for biases while designing survey methods (Hamel et al. 2013, Burton et al. 2015). For example, the rapid decline in the efficacy of our camera traps after the first day of deployment suggests reducing the exposure period would have little effect on coyote detection rates. Assuming most camera-trap studies are constrained by the number of cameras available, decreasing exposure period can allow for deployment at more locations within the same study period, and in doing so increase the precision of data-hungry spatial models that are often the end product of camera-trap studies. Given that coyotes were less likely to be detected at high temperatures, high wind speeds, and 
low pressure, a shorter exposure period may have risks if camera traps are set when weather conditions are unfavorable. Alternatively, if deployment decisions are made to maximize detection rates, camera traps set when weather conditions are optimal can greatly reduce Type II error. Wildlife managers or researchers can optimize cameratrap performance if trapping efforts are timed to take advantage of conditions that increase detection probability. For example, we found coyote detection probability to be greatest at low temperatures, presumably because thermal stress and limited resources drove coyotes to increase movement (Dillon and Kelly 2008). Therefore, deployment during winter in our study system would presumably increase coyote detection because traps would be deployed during the lowest yearly temperatures. The complexity of how detection probability is shaped by the interaction between environmental and biological conditions highlights the potential benefit of pilot studies to identify sources of detection error and adaptively change study protocols to maximize detection rates, especially when species are rare or risks associated with Type II error are high.

Obtaining reliable estimates of detection probability and subsequent sources of variation in detection is challenging when monitoring rare or highly elusive species because monitoring efforts often result in highly zero-inflated data sets that are not conducive to determining sources of detection error (Martin et al. 2005, Dénes et al. 2015). There are many similarities among Nebraska canid species (e.g., behavior, energy trade-offs, and overlaps in distribution), therefore, we assumed that coyotes may serve as a proxy for identifying sources of error in the detection probabilities of other rarer canid species, such as swift foxes. Clearly, sources of detection error may vary between species as a result of factors such as body size or social behaviors (Séquin et al. 2003, Carbone et al. 2005, Tobler et al. 2008), but when considered in a larger theoretical framework, the use of a proxy species may have value. For example, the effects on detection are likely sensitive to difference among species in body size or energy storage capacity (Clark 1994, Rowcliffe et al. 2014, Noonan et al. 2015). That canid species of all body sizes are more likely to be active when temperatures drop might be expected, but the exact threshold likely differs among species based largely on body size (e.g., Bergmann 1847, Mayr 1956). Our study takes a necessary step in identifying weather as an important source of Type II error, but further studies are necessary 
to determine the exact nature of the relationships predicting detection probabilities for other species.

\section{Management implications}

Low cost, noninvasive, and effective at detecting elusive species (Silveira et al. 2003, Long et al. 2008, Trolliet et al. 2014), camera traps have tremendous potential to help inform wildlife conservation efforts (Rowcliffe and Carbone 2008, O’Connell et al. 2011, Burton et al. 2015, Caravaggi et al. 2017), but the benefits must be measured in the reliability as a population index (Foster and Harmsen 2012, Meek et al. 2014). Given that camera traps are often used to monitor species of conservation interest, Type II error is an important concern that must be addressed (MacKenzie et al. 2002). We show that basic weather conditions affect detection probability of a common carnivore species, the coyote, that otherwise has high detection probability, adding to other known sources of Type II error common to camera traps (Newey et al. 2015). We also show that detection probability decreased exponentially over time, a pattern possibly driven by the use of scent lures. Camera traps are frequently used to observe species of conservation concern and the study of rare species is limited by patchy and sparse data already, therefore, detection biases are especially important to account for when using camera traps as a survey method. We suggest surveys address weather bias in both the study design and analysis stages of their efforts. Accounting for biases in survey designs and models will allow management and conservation efforts of elusive wildlife such as canids to increase the accuracy of population estimates, and subsequently the efficacy of conservation plans.

Acknowledgments - Funding for this project was received from the Federal Aid in Wildlife Restoration project T-86-R, administered by the Nebraska Game and Parks Commission, Nebraska Environmental Trust grant 15-202-3, Nebraska Department of Roads grant RHE-05, and in-kind support from the U.S. Department of Agriculture Forest Service Nebraska National Forest. Any use of trade, firm, or product names is for descriptive purposes only and does not imply endorsement by the U.S. Government. The Nebraska Cooperative Fish and Wildlife Research Unit is supported by a cooperative agreement among the U.S. Geological Survey, the Nebraska Game and Parks Commission, the University of Nebraska, the U.S. Fish and Wildlife Service, and the Wildlife Management Institute. We also thank Terry Messmer and reviewers for suggestions to improve the manuscript. The authors declare no conflicts of interest. 


\section{Literature cited}

Akaike, H. 1973. Information theory as an extension of the maximum likelihood principle. Pages 267-281 in B. N. Petrov and F. Csaki, editors. Second international symposium on information theory. Akademiai Kiado, Budapest.

Albrecht, M. 2015. Swift fox abundance along the Heartland Expressway Corridor in Nebraska. Nebraska Department of Transportation Research Reports, Kearney, USA.

Algar, D., G. J. Angus, M. R. Williams, and A. E. Mellican. 2007. Influence of bait type, weather and prey abundance on bait uptake by feral cats (Felis catus) on Peron Peninsula, Western Australia. Conservation Science 6:109-149.

Andelt, W. F., and S. H. Andelt. 1981. Habitat use by coyotes in southeastern Nebraska. Journal of Wildlife Management 45:1001-1005.

Andelt, W. F., and T. P. Woolley. 1996. Responses of urban mammals to odor attractants and a bait-dispensing device. Wildlife Society Bulletin 24:111-118.

Anderson, B. 1999. Grasslands and forages of Nebraska. Rangelands 21:5-8.

Bacheler, N. M., D. J. Berrane, W. A. Mitchell, C. M. Schobernd, Z. H. Schobernd, B. Z. Teer, and J. C. Ballenger. 2014. Environmental conditions and habitat characteristics influence trap and video detection probabilities for reef fish species. Marine Ecology Progress Series 517:1-14.

Bailey, L. L., D. I. MacKenzie, and J. D. Nichols. 2014. Advances and applications of occupancy models. Methods in Ecology and Evolution 5:1269-1279.

Bailey, T. N. 1971. Biology of striped skunks on a southwestern Lake Erie marsh. American Midland Naturalist 85:196-207.

Barja, I., F. J. de Miguel, and F. Bárcena. 2004. The importance of crossroads in facial marking behavior of the wolves (Canis lupus). Naturwissenschaften 91:489-492.

Barton, K. 2019. MuMIn: Multi-Model Inference. R package version 1.43.15. https://CRAN.R-project.org/package=MuMIn

Bates, D., M. Maechler, B. Bolker, and S. Walker. 2015. Fitting linear mixed-effects models using lme4. Journal of Statistical Software 67:1-48.

Bekoff, M., and E. M. Gese. 2003. Pages 467-481 in G. A. Feidhamer, B. C. Thompson, and J. A. Chapman, editors. Wild mammals of North America: biology, management, and conservation. Second edition. Johns Hopkins University Press, Baltimore, Maryland, USA.

Bergmann, C. 1847. Uber die verhaltnisse der warmeokonomie der thiere zu ihrer grosse. Gottinger Studien 3:595-708. [In German].

Bishop, A., A. Barenberg, N. Volpe, J. Riens, and R. Grosse. 2011. Nebraska land cover development. Rainwater Basin Joint Venture, Grand Island, Nebraska, USA.

Borchers, D. L., S. T. Buckland, W. E. Stephens, and W. Zucchini. 2002. Estimating animal abundance: closed populations. Volume 13. Springer Science and Business Media, London, England, United Kingdom. 
Brown, F. A., Jr., H. M. Webb, and E. J. Macey. 1957. Lag-lead correlations of barometric pressure and biological activity. Biological Bulletin 113:112-119.

Burton, A. C., E. Neilson, D. Moreira, A. Ladle, R. Steenweg, J. T. Fisher, E. Bayne, and S. Boutin. 2015. Wildlife camera trapping: a review and recommendations for linking surveys to ecological processes. Journal of Applied Ecology 52:675-685.

Caravaggi, A., P. B. Banks, A. C. Burton, C. M. V. Finlay, P. M. Haswell, M. W. Hayward, M. J. Rowcliffe, and M. D. Wood. 2017. A review of camera trapping for conservation behavior research. Remote Sensing in Ecology and Conservation 3:109-122.

Carbone, C., S. Christie, K. Conforti, T. Coulson, N. Franklin, J. R. Ginsberg, M. Griffiths, J. Holden, M. Kinnaird, R. Laidlaw, A. Lynam, D. W. Macdonald, D. Matyr, C. McDougal, L. Nath, T. O’Brien, J. Seidensticker, D. J. L. Smith, M. Sunquist, R. Tilson, and W. N. Wan Shahruddin. 2001. The use of photographic rates to estimate densities of tigers and other cryptic mammals. Animal Conservation 4:75-79.

Carbone, C., S. Christie, K. Conforti, T. Coulson, N. Franklin, J. R. Ginsberg, M. Griffiths, J. Holden, M. Kinnaird, R. Laidlaw, A. Lynam, D. W. Macdonald, D. Matyr, C. McDougal, L. Nath, T. O’Brien, J. Seidensticker, J. L. D. Smith, R. Tilson, and W. N. Wan Shahruddin. 2002. The use of photographic rates to estimate densities of cryptic mammals: response to Jennelle et al. Animal Conservation 5:121-123.

Carbone, C., G. Cowlishaw, N. J. B. Isaac, and J. M. Rowcliffe. 2005. How far do animals go? Determinants of day range in mammals. American Naturalist 165:290-297.

Caro, T. 2010. Conservation by proxy: indicator, umbrella, keystone, flagship, and other surrogate species. Island Press, Washington, D.C., USA.

Chapman, S., J. M. Omernik, J. A. Freeouf, D. G. Huggins, J. R. McCauley, C. C. Freeman, G. Steinauer, R. T. Angelo, and R. L. Schlepp. 2001. Ecoregions of Nebraska and Kansas (color poster with map, descriptive text, summary tables, and photographs). U.S. Geological Survey, Reston, Virginia, USA.

Clark, C. W. 1994. Antipredator behavior and the asset-protection principle. Behavioral Ecology 5:159-170.

Dénes, F. V., L. F. Silveira, and S. R. Beissinger. 2015. Estimating abundance of unmarked animal populations: accounting for imperfect detection and other sources of zero inflation. Methods in Ecology and Evolution 6:543-556.

Dillon, A., and M. J. Kelly. 2008. Ocelot home range, overlap and density: comparing radio telemetry with camera trapping. Journal of Zoology 275:391-398.

Faust, L. J., J. S. Simonis, R.Harrison,W.Waddell, and S. Long. 2016. Red wolf (Canis rufus) population viability analysis. U.S. Fish and Wildlife Service Final Report, Lincoln Park Zoo, Chicago, Illinois, USA.

Foster, R. J., and B. J. Harmsen. 2012. A critique of density estimation from camera-trap data. Journal of Wildlife Management 76:224-236. 
Fry, F. J. 1967. Responses of vertebrate poikilotherms to temperature. Pages 375409 in A. H. Rose, editor. Thermobiology. Academic Press, London, England, United Kingdom.

Gooch, M. M., A. M. Heupel, S. J. Price, and M. E. Dorcas. 2006. The effects of survey protocol on detection probabilities and site occupancy estimates of summer breeding anurans. Applied Herpetology 3:129-142.

Greenberg, S. 2012. Timelapse Coder Version 1.1.0.17. University of Calgary, Calgary, California, USA.

Guillera-Arroita, G., J. J. Lahoz-Monfort, D. I. MacKenzie, B. A. Wintle, and M. A. McCarthy. 2014. Ignoring imperfect detection in biological surveys is dangerous: a response to 'Fitting and interpreting occupancy models'. PLoS ONE 9:1-14.

Hamel, S., S. T. Killengreen, J. A. Henden, N. E. Eide, L. Roed-Eriksen, R. A. Ims, and N. G. Yoccoz. 2013. Towards good practice guidance in using camera-traps in ecology: influence of sampling design on validity of ecological inferences. Methods in Ecology and Evolution 4:105-113.

Kauhala, K., K. Holmala, and J. Schregel. 2007. Seasonal activity patterns and movements of the raccoon dog, a vector of diseases and parasites, in southern Finland. Mammalian Biology: Zeitschrift für Säugetierkunde 6:342-353.

Kays, R., S. Tilak, B. Kranstauber, P. Jansen, C. Carbone, M. Rowcliffe, T. Fountain, J. Eggert, and Z. He. 2011. Camera traps as sensor networks for monitoring animal communities. International Journal of Research and Reviews in Wireless Sensor Networks 1:19-29.

Kellner, K. F., and R. K. Swihart. 2014. Accounting for imperfect detection in ecology: a quantitative review. PLoS ONE 9(10):e111436.

Kucera, T. E., and R. H. Barrett. 2011. A history of camera trapping. Pages 9-26 in A. F. O'Connell, J. D. Nichols, and K. U. Karanth, editors. Camera traps in animal ecology: methods and analysis. Springer, Tokyo, Japan.

Larrucea, E. S., P. F. Brussard, M. M. Jaeger, and R. H. Barrett. 2007. Cameras, coyotes, and the assumption of equal detectability. Journal of Wildlife Management 71:1682-1689.

Long, R. A., P. MacKay, J. Ray, and W. Zielinski, editors. 2008. Noninvasive survey methods for carnivores. Island Press, Washington, D.C., USA.

Lytle, D. A. 1999. Use of rainfall cues by Abedus herberti (Hemiptera: Belostomatidae): a mechanism for avoiding flash floods. Journal of Insect Behavior 12:1-12.

MacKenzie, D. I., J. D. Nichols, J. E. Hines, M. G. Knutson, and A. B. Franklin. 2003. Estimating site occupancy, colonization, and local extinction when a species is detected imperfectly. Ecology 84:2200-2207.

MacKenzie, D. I., J. D. Nichols, G. B. Lachman, S. Droege, J. A. Royle, and C. A. Langtimm. 2002. Estimating site occupancy rates when detection probabilities are less than one. Ecology 83:2248-2255.

Martin, T. G., B. A. Wintle, J. R. Rhodes, P. M. Kuhnert, S. A. Field, S. J. Low-Choy, A. J. Tyre, and H. P. Possingham. 2005. Zero tolerance ecology: improving 
ecological inference by modelling the source of zero observations. Ecology Letters 8:1235-1246.

Mayr, E. 1956. Geographical character gradients and climatic adaptation. Evolution 10:105-108.

McCallum, J. 2013. Changing use of camera traps in mammalian field research: habitats, taxa and study types. Mammal Review 43:196-206.

McClennen, N., R. R. Wigglesworth, S. H. Anderson, and D. G. Wachob. 2001. The effect of suburban and agricultural development on the activity patterns of coyotes (Canis latrans). American Midland Naturalist 146:27-36.

Meek, P. D., G. Ballard, A. Claridge, R. Kays, K. Moseby, T. O’Brien, A. O’Connell, J. Sanderson, D. E. Swann, M. Tobler, and S. Townsend. 2014. Recommended guiding principles for reporting on camera trapping research. Biodiversity Conservation 23:2321-2343.

Nebraska Department of Natural Resources. 1969. Elevation data. https://dnr. nebraska.gov/data/elevation-data . Accessed 14 May 2019.

Newey, S., P. Davidson, S. Nazir, G. Fairhurst, F. Verdicchio, R. J. Irvine, and R. van der Wal. 2015. Limitations of recreational camera traps for wildlife management and conservation research: a practitioner's perspective. Ambio 44(Suppl 4):S624-S635.

Noonan, M. J., M. A. Rahmen, C. Newman, C. D. Buesching, and D. W. Macdonald. 2015. Avoiding verisimilitude when modelling ecological responses to climate change: the influence of weather conditions on trapping efficiency in European badgers (Meles meles). Global Change Biology 21:3575-3585.

O'Connell, A. F., J. D. Nichols, and K. U. Karanth. 2011. Camera traps in animal ecology: methods and analysis. Springer, Tokyo, Japan.

O'Connell, A. F., Jr., N. W. Talancy, L. L. Bailey, J. R. Sauer, R. Cook, and A. T. Gilbert. 2006. Estimating site occupancy and detection probability parameters for meso- and large mammals in a coastal ecosystem. Journal of Wildlife Management 70:1625-1633.

Paige, K. N. 1995. Bats and barometric pressure: conserving limited energy and tracking insects from the roost. Functional Ecology 9:463-467.

Pease, B. S., C. K. Nielsen, and E. J. Holzmueller. 2016. Single-camera trap survey designs miss detections: impacts on estimates of occupancy and community metrics. PLOS ONE 11:e0166689.

Pollock, K. H., J. D. Nichols, T. R. Simons, G. L. Farnsworth, L. L. Bailey, and J. R. Sauer. 2002. Large scale wildlife monitoring studies: statistical methods for design and analysis. Environmetrics 13:105-119.

Ripple, W. J., J. A. Estes, R. L. Beschta, C. C. Wilmers, E. G. Ritchie, M. Hebblewhite, J. Berger, B. Elmhagen, M. Letnic, M. P. Nelson, O. J. Schmitz, D. W. Smith, A. D. Wallach, and A. J.Wirsing. 2014. Status and ecological effects of the world's largest carnivores. Science 343:1241484.

Rovero, F., F. Zimmermann, D. Berzi, and P. Meek. 2013. 'Which camera trap type and how many do I need?' A review of camera features and study designs for a range of wildlife research applications. Hystrix, the Italian Journal of Mammalogy 24:148-156. 
Rowcliffe, J. M., and C. Carbone. 2008. Surveys using camera traps: are we looking to a brighter future? Animal Conservation 11:185-186.

Rowcliffe, J. M., J. Field, S. T. Turvey, and C. Carbone. 2008. Estimating density using camera traps without the need for individual recognition. Journal of Applied Ecology 45:1228-1236.

Rowcliffe, J. M., R. Kays, B. Kranstauber, C. Carbone, and P. A. Jansen. 2014. Quantifying levels of animal activity using camera trap data. Methods in Ecology and Evolution 5:1170-1179.

Schlexer, F. V. 2008. Attracting animals to detection devices. Pages 263-292 in R. A. Long, P. MacKay, J. Ray, and W. Zielinski, editors. Noninvasive survey techniques for carnivores. Island Press, Washington, D.C., USA.

Schneider, R., K. Stoner, G. Steinauer, M. Panella, and M. Humpert, editors. 2011. The Nebraska legacy project: state wildlife action plan. Second edition. Nebraska Game and Parks Commission, Lincoln, USA.

Seber, G. A. F. 1986. A review of estimating animal abundance. Biometrics 42:267-292.

Séquin, E. S., M. M. Jaeger, P. F. Brussard, and R. H. Barrett. 2003. Wariness of coyotes to camera traps relative to social status and territory boundaries. Canadian Journal of Zoology 81:2015-2025.

Sikes, R. S., W. L. Gannon, and the Animal Care and Use Committee of the American Society of Mammalogists. 2011. Guidelines of the American Society of Mammalogists for the use of wild mammals in research. Journal of Mammalogy 92:235-253.

Silveira, L., A. T. A. Jácomo, and J. A. F. Diniz-Filho. 2003. Camera trap, line transect census and track surveys: a comparative evaluation. Biological Conservation 114:351-355.

Sollmann, R., A. Mohamed, H. Samejima, and A. Wilting. 2013. Risky business or simple solution-relative abundance indices from cameratrapping. Biological Conservation 159:405-412.

Tieszen, L. L., B. C. Reed, N. B. Bliss, B. K. Wylie, and D. D. DeJong. 1997. NDVI, $\mathrm{C}_{3}$ and $\mathrm{C}_{4}$ production, and distributions in Great Plains grassland land cover classes. Ecological Applications 7:59-78.

Tobler, M. W., S. E. Carrillo-Percastegui, R. Leite Pitman, R. Mares, and G. V. N. Powell. 2008. An evaluation of camera traps for inventorying largeand medium-sized terrestrial rainforest mammals. Animal Conservation 11:169-178.

Tobler, M. W., A. Z.Hartley, S. E. Carillo-Percastegui, and G. V. N. Powell. 2015. Spatiotemporal hierarchical modelling of species richness and occupancy using camera trap data. Journal of Applied Ecology 52:413-421.

Tobler, M. W., and G. V. N. Powell. 2013. Estimating jaguar densities with camera traps: problems with current designs and recommendations for future studies. Biological Conservation 159:109-118.

Trolliet, F., M. C. Huynen, C. Vermeulen, and A. Hambuckers. 2014. Use of camera traps for wildlife studies: a review. Biology, Agronomy, Society and Environment 18:446-454. 
Wells, M. C., and M. Bekoff. 1982. Predation by wild coyotes: behavioral and ecological analyses. Journal of Mammalogy 63:118-127.

Whittington, J., C. C. St. Clair, and G. Mercer. 2005. Spatial responses of wolves to raids and trails in mountain valleys. Ecological Applications 15:543-553.

Wiens, J. A., G. D. Hayward, R. S. Holthausen, and M. J. Wisdom. 2008. Using surrogate species and groups for conservation planning and management. BioScience 58:241-252.

Wright, C. K., and M. C. Wimberly. 2013. Recent land use change in the western Corn Belt threatens grasslands and wetlands. Proceedings of the National Academy of Sciences 110:4134-4139.

Supporting information - Additional supporting material follows: Table S1 denoting technical specifications of trail cameras used for this study and Table S2 of model parameters for the stepwise selection of predictor variables for the global generalized linear mixed effects models. 


\section{Supporting Information}

Table S1. Trail camera specifications of Moultrie M-880 (model MCG-12594) and Bushnell Trophy Cam HD (model 119437). The Moultrie and Bushnell trail cameras were operated within standard operating conditions for the duration of data collection.

\begin{tabular}{lcc} 
Specification & Moultrie & Bushnell \\
\hline Optical field of view & $50^{\circ}$ & $45^{\circ}$ \\
Approximate detection range & $12 \mathrm{~m}$ & $12 \mathrm{~m}$ \\
Response time & $0.8 \mathrm{sec}$ & $0.6 \mathrm{sec}$ \\
Operating temperature range & unknown & $-20^{\circ}$ to $60^{\circ} \mathrm{C}$ \\
Price & US $\$ 119.99$ & $\mathrm{US} \$ 249.99$ \\
\hline
\end{tabular}

Table S2. Stepwise model comparison from the global generalized linear mixed-effects model (GLMM) examining weather effects on coyote occupancy in western Nebraska, USA, over 4 field seasons: Spring 2014 (21 Mar-18 Jun), Autumn 2014 (5 Sep-7 Nov), Spring 2015 (26 Mar-20 Jun), and Autumn 2015 (31 Aug-21 Dec). The global GLMM formula was: Occupancy $\sim$ Exposure period + temperature + precipitation + pressure + wind speed $+(1 \mid$ TRS $)+(1 \mid$ Datetime $)$. Using the function dredge from the MuMIn package (Barton 2019), we created and compared models using all possible combinations of the predictors from the global model.

\begin{tabular}{|c|c|c|c|c|c|c|c|c|c|c|}
\hline Model & Intercept & $\begin{array}{c}\text { Air } \\
\text { temp }\end{array}$ & Precipitation & $\begin{array}{c}\text { Barometric } \\
\text { pressure }\end{array}$ & $\begin{array}{l}\text { Wind } \\
\text { speed }\end{array}$ & $d f$ & $\begin{array}{c}\log \\
\text { likelihood }\end{array}$ & $A I C_{c}$ & $\Delta A I C_{c}$ & Weight \\
\hline Global & -6.681 & -0.241 & -0.179 & 0.119 & -0.389 & 7 & $-8,197.09$ & $16,408.17$ & 0.00 & $8.84 \mathrm{e}-\mathrm{O} 1$ \\
\hline 12 & -6.683 & -0.228 & -0.176 & - & -0.393 & 6 & $-8,200.17$ & $16,412 \cdot 34$ & 4.17 & 1.10e-o1 \\
\hline 14 & -6.677 & -0.232 & - & 0.115 & -0.340 & 6 & $-8,203.25$ & $16,418.51$ & 10.34 & $5.04 \mathrm{e}-03$ \\
\hline 10 & -6.679 & -0.220 & - & - & -0.404 & 5 & $-8,206.17$ & $16,422 \cdot 34$ & 14.17 & $7 \cdot 42 \mathrm{e}-\mathrm{O} 4$ \\
\hline 15 & -6.678 & - & -0.149 & 0.071 & -0.420 & 6 & $-8,220.96$ & $16,453 \cdot 93$ & $45 \cdot 76$ & $1.02 \mathrm{e}-10$ \\
\hline 11 & -6.680 & - & -0.149 & - & -0.422 & 5 & $-8,222.12$ & $16,454.23$ & 46.06 & 8.80e-11 \\
\hline 13 & -6.674 & - & - & 0.070 & -0.427 & 5 & $-8,225.46$ & $16,460.91$ & 52.74 & $3.12 \mathrm{e}-12$ \\
\hline 9 & -6.676 & - & - & - & -0.430 & 4 & -8226.57 & $16,461.14$ & 52.97 & $2.78 \mathrm{e}-12$ \\
\hline 8 & -6.681 & -0.285 & -0.235 & 0.147 & - & 6 & $-8,254.63$ & $16,521.27$ & 113.10 & $2.44 \mathrm{e}-25$ \\
\hline 4 & -6.683 & -0.271 & -0.232 & - & - & 5 & $-8,259 \cdot 34$ & $16,528.69$ & 120.52 & $5.98 \mathrm{e}-27$ \\
\hline 6 & -6.679 & -0.274 & - & 0.143 & - & 5 & $-8,264.46$ & $16,538.91$ & 130.74 & $3.60 e-29$ \\
\hline 2 & -6.682 & -0.259 & - & - & - & 4 & $-8,268.97$ & $16,545.94$ & 137.77 & $1.07 \mathrm{e}-30$ \\
\hline 7 & -6.674 & - & -0.192 & 0.093 & - & 5 & $-8,287 \cdot 31$ & $16,584.62$ & 176.44 & $4.29 \mathrm{e}-39$ \\
\hline 3 & -6.677 & - & -0.191 & - & - & 4 & $-8,289 \cdot 35$ & $16,586.69$ & 178.52 & $1.52 \mathrm{e}-39$ \\
\hline 5 & -6.673 & - & - & 0.093 & - & 4 & $-8,294 \cdot 30$ & $16,596.60$ & 188.43 & $1.07 \mathrm{e}-41$ \\
\hline 1 & -6.675 & - & - & - & - & 3 & $-8,296.33$ & $16,598.65$ & 190.48 & $3.84 \mathrm{e}-42$ \\
\hline
\end{tabular}

\section{Literature Cited}

Barton, K. 2019. MuMIn: Multi-Model Inference. R package version 1.43.15. https://CRAN.R-project.org/package=MuMIn 